\title{
Aerobic endurance in HIV-positive young adults and HIV-negative controls in Malawi
}

\section{E M Chisati ${ }^{1}$ and $O$ Vasseljen ${ }^{2}$}

1. Department of Physiotherapy, College of Medicine, University of Malawi, Blantyre, Malawi.

2. Department of Public Health and General Practice, Faculty of

Medicine, Norwegian University of Science and Technology (NTNU), Trondheim, Norway.

Correspondence to: Mr. E M. Chisati,

Email: echisati@gmail.com

Abstract
Background
Aerobic endurance is an important aspect of physical fitness that
enables individuals living with HIV to endure in the work place as well
as in agricultural operations in order to earn a living and improve their
quality of life. However, despite high HIV prevalence rates, the aerobic
endurance status of young Malawians living with HIV remains unknown.
The objective of this study was to determine the difference in VO
between HIV-negative and HIV-positive individuals in Blantyre, Malawi.

\section{Methods}

Fifty five participants (17 males and 38 females) who have HIV and were not taking antiretroviral medication and $78 \mathrm{HIV}$-negative participants (45 males and 33 females) performed the Rockport submaximal treadmill exercise test. Measures of body weight, post-exercise heart rate and time to walk one mile were obtained and used to predict $\mathrm{VO}_{2 \max }$. Comparisons between groups were adjusted for age differences using analysis of covariance (ANCOVA)

\section{Results}

$\mathrm{VO}_{2 \max }$ was significantly lower in HIV-positive subjects [31.1, 28.7 $33.5 \mathrm{~mL} . \mathrm{kg}-1 . \mathrm{min}-1$ (mean, $95 \% \mathrm{CI}$ )] compared with HIV-negative subjects [56.2, 54.3 - 58.1mL.kg-1.min-1].

\section{Conclusion}

Aerobic endurance was markedly reduced in HIV-positive participants compared with HIV-negative participants. Findings of the current study implicate factors associated with the HIV infection as contributors to a decreased aerobic endurance in people living with HIV.

\section{Introduction}

Human immunodeficiency virus (HIV) infection is a substantial public health problem in Malawi. Since 1985, when the first HIV case was diagnosed, prevalence has increased significantly among persons aged 15 to 49 , rising to $16.2 \%$ in 1999 before decreasing and stabilizing at about $12 \%$ since $2005^{1}$. This translates into 800,000 to 1 million Malawians living with HIV. With a current prevalence of about $10 \%$, $\mathrm{HIV}$ is now the leading cause of death amongst 15 to 49 yearolds in Malawi ${ }^{2}$. Most individuals living with HIV experience muscle pain, loss of lean body mass and fatigue which lead to decreased aerobic endurance, consequently limiting their work participation and activities of daily living ${ }^{3}$.

Although evidence about reduced aerobic endurance among $\mathrm{HIV}$ infected individuals exists ${ }^{4-6}$. this knowledge is based on Western populations, which have different physical activity habits from Sub Saharan African populations. Aerobic endurance of an individual is affected by physical activity habits, body composition, gender, age and genetic factors as well as geographical living area ${ }^{7}$. Thus, aerobic endurance may differ significantly among various populations. Despite the high prevalence of HIV in Malawi, knowledge about the aerobic endurance status of Malawians living with HIV remains lacking. This study aimed at quantifying the aerobic endurance status of Malawians living with HIV by specifically determining the difference in maximal oxygen uptake between HIV-positive individuals and HIV-negative individuals in Blantyre, Malawi.

\section{Methods}

\section{Study design Study sample and recruitment}

This was a cross sectional study in which 17 male and 38 female adults $(n=55)$ with HIV and 45 male and 33 female HIV-negative controls $(n=78)$ participated. All participants were recruited from the voluntary counselling and testing (VCT) clinic of Queen Elizabeth Central Hospital (QECH) in Blantyre, Malawi. Participants were asked by their attending physicians for permission and were contacted by the researcher who explained the nature of the study and assessed eligibility of those who agreed to participate. Informed consent was obtained from all eligible and willing individuals to participate in the study, which was approved by the University of Malawi's College of Medicine Research and Ethics Committee (COMREC). The study is in conformity with the laws of Malawi and the Declaration of Helsinki.

\section{Selection criteria}

Male and female adults aged 18 to 35, either positive or negative for HIV at the QECH VCT clinic were contacted to be included in the study. Clients who tested positive were included if they were in the early (asymptomatic) stage of the infection and not yet taking antiretroviral (ART) medications. ART medications are life-prolonging drugs prescribed in the later (symptomatic) stages of HIV infection. Clients with any known neurologic, orthopaedic, haematologic, pulmonary or cardiorespiratory limitations or who were taking any medication that would contraindicate treadmill testing or alter cardiorespiratory response to exercise were excluded. All HIV-positive clients with a cluster of differentiation 4 (CD4) cell count less than 350 cells.mm-3 were also excluded. Since HIV infects CD4+ cells, an individual's cell count below 350 cells.mm-3 is considered a cut-off point for starting receiving ART medication ${ }^{8}$.

\section{Test equipment}

A motorized treadmill (Trojan Marathon 200) interfaced with a microprocessor to control speed and time was used to conduct the exercise test. A Polar heart rate monitor (FT 4) was used to obtain post-exercise heart rate and time to walk a one mile equivalent on the treadmill. A body weight scale and a drop-down tape measure were used to obtain height and body weight measurements respectively.

\section{Variables}

\section{Height and body weight}

Height and body weight measurements for each participant were collected using a body weight scale and tape measure before the exercise test. Height measurements were obtained using a drop down tape measure fixed at about two metres on a wall. The participants removed their shoes before taking the measurement and stood with their backs against a wall while facing directly forward. The backs of their feet, calves, buttocks, upper backs and the backs of their heads were all in contact with the wall. The drop-down measuring device was 
lowered until it rested gently on the top of each participant's head, after which the measurements were recorded. To obtain body weight measurements, the scale was set to zero before each participant stepped on it. The participants were asked to remove any heavy items from their pockets such as keys and any heavy clothing such as jackets, woolen jerseys, and shoes before stepping on the scale. Then the participants stepped on the scale and stayed still for a short time while facing straight ahead, after which the measurement was recorded. Height and body mass measurements were used to calculate body mass index (BMI) scores.

\section{$V_{2 \max }$ and post-exercise heart rate}

Maximal oxygen uptake $\left(\mathrm{VO}_{2 \mathrm{max}}\right)$ was calculated as a measure of aerobic endurance. $\mathrm{VO}_{2 \max }$ was predicted from the Rockport one mile submaximal exercise test ${ }^{9}$. The Rockport one mile submaximal exercise test has been proven to be a reliable and valid protocol in predicting $\mathrm{VO} 2 \mathrm{max}$ in untrained subjects $^{10,11}$. In addition, the Rockport one mile submaximal test lessens problems of exhaustion and injuries associated with exercise testing ${ }^{11}$. Maximal oxygen uptake scores were predicted from the Rockport one mile walking test formula: $V O_{2 \max }=132.853-(0.0769 \times$ body mass $)-(0.3877 \times$ age $)+$ $(6.315 \times$ gender $)-(3.2649 \times$ time $)-(0.1565 \times$ HR $)$.

The procedure of the test started with a warm up of about eight to ten minutes. The warm up was aimed at familiarizing the participants with treadmill walking and also to ensure safety. After warming up, the participants were asked to walk 1.6 kilometres (one mile) as fast as possible on a motorized treadmill, without jogging or running. The participants' postexercise heart rates (PoExHR) and times to complete the one mile distance were recorded using a Polar heart rate monitor. To obtain post-exercise heart rates, the participants each wore a Polar H7 Bluetooth smart heart rate sensor secured with a strap around the chest and a heart rate monitor watch on the wrist while exercising. The sensor, which contains a transmitter rested below the breast, detected the electrical activity of the heart and transmitted the information to the monitor watch where it was displayed. Time taken by each participant to complete one mile was also displayed on the monitor watch and was recorded immediately after the exercise test.The treadmill test was performed twice by each participant to obtain an average heart rate for calculating $\mathrm{VO}_{2 \max }$. An active recovery period of two to five minutes was allowed immediately after the first test in preparation for the second test. The exercise tests were done individually. Each participant was scheduled for his or her own time for the exercise. The supervisor of the exercise tests was blinded of the participants' HIV statuses in order to obtain more reliable results.

\section{Sample size}

The sample size calculation was based on previous VO2max studies performed on individuals with HIV and healthy subjects $^{12,13}$. From the studies, it was estimated that the effect size difference in VO2max between HIV-positive and HIV-negative participants would be $5 \mathrm{~mL} . \mathrm{kg}$ - 1 . min-1 with a standard deviation of nine per group. To achieve $80 \%$ power to detect a $5 \mathrm{~mL} . \mathrm{kg}-1 . \mathrm{min}-1$ difference in mean VO2max, with an alpha of 0.05 , using a two-sided test, it was estimated that 52 subjects in each group would be required. Sample size calculations were done using the $G *$ Power version 3.1.6 computer application.

\section{Data analysis}

IBM SPSS 21 was used to analyse the data. Descriptive statistics with mean and standard deviation were used to characterize data variables. All data assumed a normal distribution and the independent samples t-test was used to analyse differences between HIV-negative and HIV-positive groups, and differences are reported with mean and 95\% confidence intervals (CI). Analysis of covariance (ANCOVA) was used to analyse differences between groups adjusted for age differences. All statistical tests were two - sided and $\mathrm{p}$ values of were considered statistically significant.

\section{Results}

Baseline characteristics of participants are presented in Table 1. Mean value of age was significantly higher $(p=0.01)$ for HIV-positive participants $(28.6 \pm 4.4$ years $)$ as compared to that of HIV-negative participants $(21.1 \pm 2.9$ years). When stratified by sex, there were significant differences in mean age $(\mathrm{p}=0.01)$ between HIV-negative and HIV-positive males $(21.2 \pm 2.2$ years versus $29.4 \pm 4.2$ years), as well as HIVnegative and HIV-positive females $(20.9 \pm 3.7$ years versus $28.1 \pm 4.5$ years). There were no significant differences in mean values for height, weight and body mass index between HIV-negative and HIV-positive participants (Table 1). The mean value of height was significantly lower $(p=0.01)$ in HIV-negative males compared to HIV-positive males. Small differences were seen for height in females and weight in both sexes (Table 2).

The overall and age-adjusted mean values of VO2max were significantly lower $(p=0.01)$ among HIV-positive participants compared to HIV-negative participants (31.1 mL.kg-1.min-1 versus $56.1 \mathrm{~mL} \cdot \mathrm{kg}-1 . \mathrm{min}-1, \mathrm{p}=0.01)$ (Table $3)$. When compared within sexes, $\mathrm{VO} 2 \mathrm{max}$ was significantly lower $(\mathrm{p}=0.01)$ in HIV-positive individuals than HIVnegative individuals in both sexes (Table 4).

TABLE 1: BASELINE CHARACTERISTICS OF PARTICIPANTS

TABLE1: BASELINE CHARACTERISTICS OF PARTICIPANTS

$\begin{array}{cccc}\text { ALL } & \text { HIV- } & \text { HIV+ } & \\ \text { SUBJECTS } & \text { SUBJECTS } & \text { SUBJECTS } & \text { P } \\ (\mathrm{n}=133) & (\mathrm{n}=78) & (\mathrm{n}=55) & \text { VALUE }\end{array}$

$\begin{array}{lllll}\text { Age }(\mathrm{yrs}) & 24.2 \pm 5.2 & 21.1 \pm 2.9 & 28.6 \pm 4.4 & 0.01 \\ \text { Height }(\mathrm{cm}) & 161.9 \pm 7.9 & 162.2 \pm 6.9 & 161.4 \pm 9.2 & 0.58 \\ \text { Weight }(\mathrm{kg}) & 58.4 \pm 9.1 & 58.7 \pm 7.4 & 58.05 \pm 11.1 & 0.66 \\ \text { BMI }\left(\mathrm{kg} / \mathrm{m}^{2}\right) & 22.3 \pm 3.1 & 22.3 \pm 2.5 & 22.3 \pm 3.6 & 0.97\end{array}$

All data are in mean $\pm S D ; S D=$ standard deviation; $B M I=$ body mass inder. 
TABLE 2: GROUP DIFFERENCES WITHIN SEX

\begin{tabular}{|c|c|c|c|c|c|c|}
\hline & \multicolumn{3}{|c|}{ Male $(n=62)$} & \multicolumn{3}{|c|}{ Female $(n=71)$} \\
\hline & $\begin{array}{l}\text { HIV - } \\
(n=45)\end{array}$ & $\begin{array}{l}\mathrm{HIV}+ \\
(\mathrm{n}=17)\end{array}$ & $\begin{array}{c}\mathrm{P} \\
\text { Value }\end{array}$ & $\begin{array}{l}\text { HIV - } \\
(n=33)\end{array}$ & $\begin{array}{l}\text { HIV + } \\
(n=38)\end{array}$ & $\begin{array}{c}\mathrm{P} \\
\text { Value }\end{array}$ \\
\hline Age (years) & $21.2 \pm 2.2$ & $29.4 \pm 4.2$ & 0.01 & $20.9 \pm 3.7$ & $28.1 \pm 4.5$ & 0.01 \\
\hline Height (cm) & $166 \pm 5.3$ & $171.6 \pm 7.7$ & 0.01 & $157 \pm 5.2$ & $156 \pm 5.4$ & 0.93 \\
\hline Weight (kg) & $60.6 \pm 6.8$ & $61.4 \pm 10.2$ & 0.72 & $56.2 \pm 7.6$ & $56.5 \pm 11.3$ & 0.89 \\
\hline BMI $\left(\mathrm{kg} / \mathrm{m}^{2}\right)$ & $21.9 \pm 2.1$ & $20.8 \pm 2.8$ & 0.09 & $22.8 \pm 2.8$ & $22.9 \pm 3.9$ & 0.89 \\
\hline
\end{tabular}

All data are in mean $\pm S D ; S D=$ standard deviation; $B M I=$ body mass index.

\section{TABLE 3: GROUP DIFFERENCES ADIUSTED FOR AGE}

\begin{tabular}{|c|c|c|c|}
\hline & $\begin{array}{l}\text { HIV - } \\
(n=78)\end{array}$ & $\begin{array}{l}\mathrm{HIV}+ \\
(\mathrm{n}=55)\end{array}$ & PValue \\
\hline $\mathrm{VO}_{2 \max }$ & 56.2 & 31.1 & 0.01 \\
\hline$\left(\mathrm{mL} \cdot \mathrm{kg}^{-1} \min ^{-1}\right)$ & $(54.3,58.1)$ & $(28.7,33.5)$ & \\
\hline PoExHR & 121.7 & 123.9 & 0.68 \\
\hline (bpm) & $(116.3,127.2)$ & $(117.0,130.7)$ & \\
\hline I mile time & 12.8 & 19.8 & 0.01 \\
\hline$(\min )$ & $(12.4,13.2)$ & $(19.3,20.4)$ & \\
\hline
\end{tabular}

Data are in mean wilh $95 \%$ confidence interval adjusted for age (ANCOVA).mL' $\mathrm{kg}^{-1 /} \mathrm{min}$ I' millilitres per kilogram per minute, PoExHR = post-exercise heart rate, Imile time = time taken to walk 1 mile distance, $b p m=$ beats per minute.

TABLE 4: GROUP DIFFERENCES WITHIN SEX ADJUSTED FOR AGE

\begin{tabular}{|c|c|c|c|c|c|c|}
\hline & & Male $(n=6$ & & Fem: & le $(n=71)$ & \\
\hline & $\begin{array}{l}\text { HIV - } \\
(n=45)\end{array}$ & $\begin{array}{l}\text { HIV + } \\
(n=17)\end{array}$ & $\begin{array}{c}\mathrm{P} \\
\text { Value }\end{array}$ & $\begin{array}{l}\text { HIV - } \\
(n=33)\end{array}$ & $\begin{array}{l}\mathrm{HIV}+ \\
(\mathrm{n}=38)\end{array}$ & $\begin{array}{c}\mathrm{P} \\
\text { Value }\end{array}$ \\
\hline $\begin{array}{l}\mathrm{VO}_{2 \max } \\
\left(\mathrm{mL} \cdot \mathrm{kg}^{-1} \cdot \mathrm{min}^{-1}\right)\end{array}$ & $\begin{array}{c}59.8 \\
(57.6,62.0)\end{array}$ & $\begin{array}{c}38.3 \\
(33.9,42.7)\end{array}$ & 0.01 & $\begin{array}{c}50.3 \\
(48.3,52.4)\end{array}$ & $\begin{array}{c}28.7 \\
(26.9,30.6)\end{array}$ & 0.01 \\
\hline $\begin{array}{l}\text { PoExHR } \\
\text { (bpm) }\end{array}$ & $\begin{array}{c}125.6 \\
(117.5,133.7)\end{array}$ & $\begin{array}{c}118.3 \\
(102.2,134.4)\end{array}$ & 0.48 & $\begin{array}{c}117.5 \\
(109.9,125.1)\end{array}$ & $\begin{array}{c}125.4 \\
(118.5,132.4)\end{array}$ & 0.17 \\
\hline $\begin{array}{l}\text { Imile time } \\
(\min )\end{array}$ & $\begin{array}{c}12.3 \\
(11.8 .12 .7)\end{array}$ & $\begin{array}{c}19.3 \\
(18.3 .20 .3)\end{array}$ & 0.01 & $\begin{array}{c}13.7 \\
(13.1,14.3)\end{array}$ & $\begin{array}{c}20 \\
(19.4,20.5)\end{array}$ & 0.01 \\
\hline
\end{tabular}

Data are in mean with 95\% confidence Interval adjusfed for age (ANCOVA). $\mathrm{mL}^{-1 / \mathrm{kg}^{-1 /}} \mathrm{min}^{-1}=$ millilitres per kilogram per minute, PoExHR - post exercise heart rate, Imile time - time taken to walk 1 mile distance, $b \mathrm{pm}=$ beats per minute.

\section{Discussion}

Results of this study reveal that HIV-positive individuals had a markedly lower aerobic endurance measured as $\mathrm{VO}_{2 \max }$ than HIV-negative individuals. Decreased aerobic endurance has been previously reported in both adolescents ${ }^{5}$ and adults, ${ }^{4,6}{ }^{14-16}$ living with HIV in Western populations. Results of the current study are in agreement with these previous reports that have underscored diminished aerobic endurance in people who have HIV. Whereas a reduced $\mathrm{VO}_{2 \max }$ of about $54 \%$ to $85 \%$ in HIV-positive individuals in most western populations has been reported, ${ }^{36-38}$ a decrease in $\mathrm{VO}_{2 \max }$ of $45 \%$ in HIV-positive individuals was revealed in the present study. The smaller $\mathrm{VO}_{2 \max }$ decrease in the present study could be due to active lifestyle habits among Malawian populations compared to Western populations. In Malawi, a large percentage of the population is involved in manual labour and agricultural operations which demand considerable physical capacity. Lifestyle activities such as walking long distances to work-places, pushing heavy levers in industries, land preparation and post-harvest processing of farm produce increases physical capacity among Malawians, which may result in increased aerobic endurance compared to Western populations. While most of the previous studies identified aerobic impairments in a mixture of HIV-positive participants taking antiretroviral (ART) medication and those not taking ART medication (pre-ART) ${ }^{4-6},{ }^{14-16}$ the present study only included participants in the pre-ART stage of their infection. Previous studies have suggested factors such as HIV infection and inflammation, impaired muscle oxygen extraction and utilization due to ART medication, and reduced physical activity as mechanisms behind diminished aerobic endurance in individuals living with HIV. ${ }^{6,14-17}$

Cade et al., reported impaired aerobic endurance identified by decreased muscle oxygen extraction and utilization only in individuals with HIV who were taking ART medication and not in those who were not taking ART medication, thus implicating ART medication as the primary contributor to decreased muscle oxygen extraction and utilization in individuals living with $\mathrm{HIV}^{17}$. The present study, however, which included only pre-ART participants found noticeably lower aerobic endurance levels in these pre-ART participants compared to HIV-negative controls suggesting that HIV infection and inflammation plays a role in the reduced aerobic endurance observed in people who have HIV. $\mathrm{VO}_{2 \max }$ is the product of central circulatory oxygen delivery and peripheral tissue oxygen extraction ${ }^{18,19}$. Oxygen delivery is regulated by mechanisms that control cardiac output and the shunting of blood to tissues of high oxygen demand. Oxygen extraction is affected by the intramuscular distribution of blood to active muscle fibers, oxygen diffusion distance associated with the muscle fibers, mitochondria density, and by the concentration of the rate limiting enzymes of oxidative phosphorylation. It has been reported that women achieve lower $\mathrm{VO}_{2 \max }$ scores of about $15 \%$ to $30 \%$ below those of male counterparts in healthy populations ${ }^{12,13,19}$. In the present study, $\mathrm{VO}_{2 \max }$ was $16 \%$ lower in females compared to males in HIV-negative individuals while in HIV-positive individuals, VO2max was 25\% lower in females compared to males. Findings from the present study are consistent with previous studies that found lower $\mathrm{VO}_{2 \max }$ in females compared with males in healthy ${ }^{13,20}$ as well as HIV-positive participants ${ }^{4,5}$. Lower values of $\mathrm{VO}_{2 \max }$ in women are a result of lower haemoglobin and blood volume, smaller stroke 
volume and smaller muscle mass compared to males ${ }^{19}$. None of the participants in the current study had any known neurologic, haematologic or cardiopulmonary limitations or were taking ART medication that would affect their VO It is most likely that the reduced aerobic endurance observed in HIV-positive participants in the present study resulted from HIV infection-related limitations. However, specific mechanisms responsible for diminished aerobic endurance in HIV-positive individuals could not be determined by the methods of the present study. Blood volume and flow may limit oxygen delivery to the muscles and eventually affect an individual's $\mathrm{VO}_{2 \max }{ }^{21}$. Most individuals living with HIV are vulnerable to anaemia, ${ }^{22,23}$ and a compromised blood volume reduces oxygen transport capacity which in turn reduces arterial-venous content difference. A compromised arterialvenous content difference leads to a decreased $\mathrm{VO}_{2 \max }{ }^{24}$ Pothoff and Wassermann reported a mean haemoglobin of $13.5 \pm 1.3 \mathrm{~g} \cdot \mathrm{dL}-1$ in HIV-positive individuals compared with $15.3 \pm 0.8$ g.dL- 1 in the control group ${ }^{16}$. This difference could account for a $12 \%$ reduction in $\mathrm{VO}_{2 \max }$ in the HIV-positive individuals. Furthermore, in a study by Johnson et al., five of the nine HIV-positive participants with a markedly reduced $\mathrm{VO}_{2 \max }$ were anaemic with a haematocrit less than $45 \%{ }^{14}$. In the current study HIV-positive individuals had a reduced $\mathrm{VO}_{2 \max }$ of $31.1 \mathrm{~mL} . \mathrm{kg}-1 . \mathrm{min}-1$ compared with $56.2 \mathrm{~mL} . \mathrm{kg}-1$. min-1 in non HIV infected individuals, which translates to a $45 \%$ reduction in $\mathrm{VO}_{2 \max }$ in HIV-positive individuals. Results from the present study may support the suggestion that reduced aerobic endurance in HIV-positive individuals could at least be partly explained by blood volume limitations. Since anaemia may be a primary expression of HIV infection, it may be an important contributor to a reduced aerobic endurance observed in people living with HIV.

Cardiac output and blood volume measurements to support this claim were not done in the current study. Existing knowledge on aerobic endurance supports the idea of exercise training to improve aerobic endurance in individuals living with HIV in Western populations ${ }^{15,25,26}$. Three meta - analyses performed for $\mathrm{VO}_{2 \max }$ among HIV-positive individuals reveal a significant improvement in $\mathrm{VO}_{2 \max }$ of $2.63 \mathrm{~mL} . \mathrm{kg}-1$.min1 for participants in aerobic exercise intervention groups compared with the non-exercising groups ${ }^{25}$. Aerobic exercise training has been proven to increase blood volume via two mechanisms: (1) an increase in hormones that cause the kidney to retain water thereby increasing blood plasma and (2) a boost in a plasma protein product that leads to more blood plasma ${ }^{27}$. An increased blood plasma volume reduces the blood's viscosity. Reduced blood viscosity improves blood flow, especially in smaller blood vessels. Consequently, improved blood flow enhances delivery of oxygen to the working muscles. It is possible, therefore, that an aerobic exercise programme could improve aerobic endurance of Malawians living with HIV, although the effects of exercise training on the aerobic endurance levels of Malawians who have HIV are yet to be explored.

\section{Study limitations}

There was a significant difference in mean age between HIV-positive and HIV-negative participants. Although mean age difference was controlled, the difference in $\mathrm{VO}_{2 n}$ may to some extent, be attributed to age bias. In addition, measurements of cardiac output and blood volume were not done to establish whether central and peripheral physiological limitations to $\mathrm{VO}_{2 \max }$ were present in young Malawian adults living with HIV. Subsequent research with measurements of cardiac output and blood volume will further the understanding of aerobic endurance of Malawians living with HIV.

\section{Conclusion}

The present study has revealed that young Malawian adults who are in the early stages of HIV infection have reduced aerobic endurance levels compared to HIV-negative young adults. VO2max was significantly lower among HIV-positive individuals than among HIV-negative individuals. Further research on the effects of exercise interventions to improve aerobic endurance among Malawians living with HIV is therefore recommended.

\section{References}

1. World Health Organization. Malawi Country Office: 2009 Annual Report.; 2009.

2. National AIDS Commission. Malawi HIV and AIDS Extended National Action Framework. 2012;(August 2009):2010-2012.

3. Rusch M, Nixon S, Schilder A, Braitstein P, Chan K, Hogg RS. Prevalence of activity limitation among persons living with HIV/AIDS in British Columbia. Can J Public Health. 2004;95(6):437-40.

4. Cade WT, Fantry LE, Nabar SR, Keyser RE. Decreased peak arteriovenous oxygen difference during treadmill exercise testing in individuals infected with the human immunodeficiency virus. Arch Phys Med Rehabil. 2003;84(11):1595-1603.

5. Keyser RE, Peralta L, Cade WT, et al. Functional Aerobic Impairment in Adolescents Seropositive for HIV : A Quasiexperimental Analysis. 2000:1479-1484.

6. Oursler KK, Sorkin JD, Smith B a, Katzel LI. Reduced aerobic capacity and physical functioning in older HIV-infected men. AIDS Res Hum Retroviruses. 2006;22(11):1113-21.

7. Grigaliūnienè, A., Ramonas, A., Čelutkienè, J., Šileikienè V, Rudys, A., Juocevičiu, A., \& Laucevičiu A. Cardiorespiratory Parameters of Exercise Capacity in a Healthy Lithuanian Population: The Pilot Study. Hell J Cardiol. 2013;54:107-118.

8. World Health Organization. Interim WHO clinical staging of HIV/ AIDS and HIV/AIDS case definitions for surveillance: African region.; 2005.

9. Kline, G.M., Porcari, J.P., Hintermeister, R., Fredson, P.S., Ward, A., McCarron, R.F., Ross, J., \& Rippe JM. Estimation of VO2max from a one mile track walk, gender, age and body composition. Med Sci Sport Exerc. 1987; 19:253-259.

10. Weiglein L, Herrick J, Kirk S, Kirk EP. The 1-mile walk test is a valid predictor of $\operatorname{VO}(2 \max )$ and is a reliable alternative fitness test to the 1.5-mile run in U.S. Air Force males. Mil Med. 2011;176(6):66973.

11. Hunt BR, George JD, Vehrs PR, Fisher AG, Fellingham GW. Validity of a Submaximal I-Mile Track Jog Test in Predicting V0, max in Fit Teenagers. Pediatr Exerc Sci. 2000;12:80-90.

12. De Lorenzo A, Meirelles V, Vilela F, Souza FCC. Use of the Exercise Treadmill Test for the Assessment of Cardiac Risk Markers in Adults Infected with HIV. J Int Assoc Physicians AIDS Care (Chic). 2012;00(0):1 -7. doi:10.1177/1545109712460098.

13. Edvardsen E, Scient C, Hansen BH, Holme IM, Dyrstad SM, Anderssen SA. Reference values for cardiorespiratory response and fitness on the treadmill in a 20 - to 85 -year-old population. Chest. 2013;144(1):241-8.

14. Johnson JE, Anders GT, Blanton HM, et al. Exercise Dysfunction in Patients Seropositive for the Human Immunodeficiency Virus. Am J Respir Crit Care Med . 1990;141 (3 ):618-622. 
15. Perna FM, LaPerriere A, Klimas N, et al. Cardiopulmonary and CD4 cell changes in response to exercise training in early symptomatic HIV infection. Med Sci Sport Exerc. 1999;31(7):973 - 979.

16. Pothoff G, \& Wassermann K OH. Impairment of exercise capacity in various groups of HIV-infected patients. Respir Int Rev Thorac Dis. 1994;61:80-85.

17. Cade WT, Fantry LE, Nabar SR, Shaw DK, Keyser RE. A comparison of Qt and a-vO2 in individuals with HIV taking and not taking HAART. Med Sci Sports Exerc. 2003;35(7):1108-17.

18. McArdle W, Katch F, Katch V. Exercise physiology: Nutrition, energy, and human performance. 7th ed. Philadelphia: Lippincott Williams \& Wilkins; 2010:275.

19. Fletcher GF, Balady GJ, Amsterdam E a., et al. Exercise Standards for Testing and Training: A Statement for Healthcare Professionals From the American Heart Association. Circulation. 2001;104(14):1694-1740.

20. Miller GS, Dougherty PJ GJ and CS. Comparison of cardiorespiratory response of moderately trained men and women using two different treadmill protocols. strength Cond Res. 2007;21(4):1067-1071.

21. Bassett DR, Howley ET. Limiting factors for maximum oxygen uptake and determinants of endurance performance. Med Sci Sports Exerc. 2000;32(1):70-84.
22. Calis JCJ, van Hensbroek MB, de Haan RJ, Moons P, Brabin BJ, Bates I. HIV-associated anemia in children: a systematic review from a global perspective. AIDS. 2008;22(10):1099-112.

23. Jaganath D, Walker a S, Ssali F, et al. HIV-Associated Anemia After 96 Weeks on Therapy: Determinants Across Age Ranges in Uganda and Zimbabwe. AIDS Res Hum Retroviruses. 2014;30(00):1 - 8 . doi:10.1089/aid.2013.0255.

24. Stringer WW. Mechanisms of exercise limitations in HIV+ individuals. Med Sci Sport Exerc. 2000;32(7):S412 - S421.

25. Brien OK, Nixon S, Am T, Glazier R. Aerobic exercise interventions for adults living with HIV / AIDS ( Review ). Cochrane database Syst Rev Online. 2010;(8).

26. Stringer WW, Berezovskaya M, O'Brien WA, Beck CK, Casaburi R. The effect of exercise training on aerobic fitness, immune indices, and quality of life in HIV+ patients. Med Sci Sport Exerc. 1998;30(1):11 -16 .

27. Gledhill N. Blood doping and related issues. A brief review. Med Sci Sport Exerc. 1982;14(3):183 -189. 